\title{
Reporte del tiempo: presente e historia
}

\author{
DANIEL INCLÁN Y AURELIA VALERO
}

En este artículo se plantea que la llamada crisis de la historia en nuestros días responde a una desarticulación progresiva entre el régimen de temporalidad y el discurso historiográfico contemporáneos, resultado de la emergencia de distintas formas de experiencia. El tema de la violencia, en tanto campo de observación y experimentación privilegiado, funciona como un medio para explorar dicho problema, proponer un ángulo distinto para pensar en el tiempo histórico e invitar a buscar nuevos modos de representación y registros narrativos.

PALABRAS CLAVE: violencia, historia del tiempo presente, representación, estéticas de la violencia, régimen de temporalidad, discurso historiográfico

\section{Keeping Time: Present and History}

This article contends that the present crisis of history is due to a continuous disarticulation between today's temporality and the contemporary historiographical discourse, brought about by the emergence of different forms of experience. Considered as an exceptional field for observation and experimentation, the theme of violence works as a means to analyze such problem, to find different conceptions of historical time, and to explore new modes of representation and narrative voices.

DANIEL INCLÁN

Instituto de Investigaciones Económicas, Universidad Nacional Autónoma de México, Ciudad de México, México ttessiss@gmail.com AURELIA VALERO Unidad de Investigación sobre Representaciones Culturales y Sociales, Universidad Nacional Autónoma de México, Morelia, Michocán, México aureliavalero@gmail.com
KEYWORDS: violence, history of the present, representation, aesthetics of violence, time regime, historical discourse 
Filosóficamente la memoria no es menos prodigiosa que la adivinación del futuro; el día de mañana está más cerca de nosotros que la travesía del Mar Rojo por los hebreos, que, sin embargo, recordamos (Borges, 1993: 224).

\author{
Este concepto de un presente que no es tránsito, sino \\ en el cual el tiempo está firme y ha entrado en un \\ estado de detenimiento, es algo a lo que la dialéctica \\ materialista no puede renunciar. Puesto que este \\ concepto define precisamente el presente en el cual, en \\ cada caso, se escribe la historia (Benjamin, 2008: 113).
}

ace ya varias décadas que la palabra "crisis" resuena, con la puntualidad de un péndulo, en la voz de los practicantes de la historia. Suele hacerse referencia a una triple insuficiencia de la disciplina. Por una parte, la que concierne a la dificultad para reconstruir o incluso entender un pasado progresivamente complejo, ambiguo y reticente ante los moldes que encuadran las narrativas más tradicionales, estructuradas en función de premisas como la objetividad y herramientas como la cronología. Más grave aún resulta, sin embargo, la crítica que apunta a su creciente inocuidad, expresada en la reconocida ineficacia para despertar un interés allende los circuitos especializados, y con ello, para convocar e interpelar desde el presente. Por último, y como consecuencia del punto anterior, no menos preocupante parece el agotamiento de lo que podría denominarse su fuerza retórica, entendida como la habilidad para producir un efecto o reacción entre sus destinatarios 
potenciales. El poder movilizador de la historia, en su orientación hacia el futuro, aparece así disminuido, por no decir anulado. ${ }^{1}$

Al tomar estos juicios con la seriedad requerida, parece que la historia, incapaz de captar y atender las exigencias del pasado, el presente y el futuro, ha perdido contacto con el tiempo, o para ser más precisos, lo que se halla en juego es la noción misma de "tiempo histórico". El cuestionamiento de la disciplina no sería, desde esa perspectiva, sino un síntoma de una situación más amplia, en la medida en que, como bien apunta Giorgio Agamben:

Cada concepción de la historia va siempre acompañada por una determinada experiencia del tiempo que está implícita en ella, que la condiciona y que precisamente se trata de esclarecer. Del mismo modo, cada cultura es ante todo una determinada experiencia del tiempo y no es posible una nueva cultura sin una modificación de esa experiencia (2007: 131).

Hacer referencia a una crisis del tiempo histórico - concebido alternativamente como aquel que se establece de manera colectiva y el que construyen los historiadores-, supondría, por consiguiente, un desfase entre la disciplina y su materia, la misma que le presta a la vez contenido y viabilidad. Del mismo modo, entrañaría ya no cierta dislocación entre la vivencia y la escritura, fenómeno siempre presente, sino la imposibilidad de conducir aquélla hacia el momento de su legibilidad.

Más que una pérdida del sentido, sin embargo, en este horizonte parece anunciarse una reconfiguración de la experiencia, en sus dimensiones social y temporal, así como un entrelazamiento distinto con varias formas narrativas, las cuales, de adoptar la propuesta clasificatoria de Reinhart Koselleck, podrían reducirse a tres. La primera concierne a las anotaciones tendentes a consignar y explicar acontecimientos únicos, en un ejercicio de índole personal que practica un individuo. Con la palabra alemana Aufschreiben se enunciaría dicha actividad. Fortschreiben, por su parte, designa el tipo de relatos que ligan y vehiculan experiencias reiteradas, marcadas por la intersubjetividad. Las experiencias derivadas de fuentes del pasado, ordenadas en función de cierta teleología o simplemente por medio de la estructura que impone la retrospección, encontrarían, por último, un cauce en el Umschreiben o reescritura. Sin que estas categorías se sucedan de manera lineal, completa o inequívoca, en el tránsito de una a otra se refleja, por igual, el camino que condujo de las historias, en plural, a la historia como colectivo singular (Koselleck, citado en Leonhard, 2013: 382). ${ }^{2}$ Ese desarrollo implicaría, no sólo la apertura hacia registros narrativos de pretensiones universalistas, y con el transcurso del tiempo, más afines al ideal de la ciencia, sino un nexo constante entre régimen de temporalidad y discurso historiográfico. Se entiende así que, al culminar su estudio sobre la emergencia y resignificación del término a mediados del siglo xix, Koselleck afirmara que "la expresión 'la historia' anunciaba el comienzo de

No obstante, numerosas razones incitan a recelar de diagnósticos semejantes. Una de ellas radica en el carácter reiterado, incluso cíclico, con que se recurre a esta clase de evaluaciones. Sin denotar el punto decisivo en que una situación empieza a resolverse, ora anunciando una inminente mejoría, ora como el último estertor de un cuerpo moribundo, es difícil que el término "crisis" resulte apropiado para caracterizar una condición que al parecer se ha normalizado. Por lo demás, sea que se tome como referencia el ritmo de la producción historiográfica o el número de egresados de este tipo de programas, hay pocos indicios que sugieran un estado endémico o de postración en los ámbitos profesionalizados. Por lo mismo, a reserva de evitar sucumbir ante el catastrofismo, tanto el imperativo de reflexividad como la responsabilidad crítica exigen ahondar en los motivos que subyacen en un panorama de malestar extendido, éste sí incuestionable. Para un análisis in extenso de la noción de "crisis", véase Koselleck (2007). 


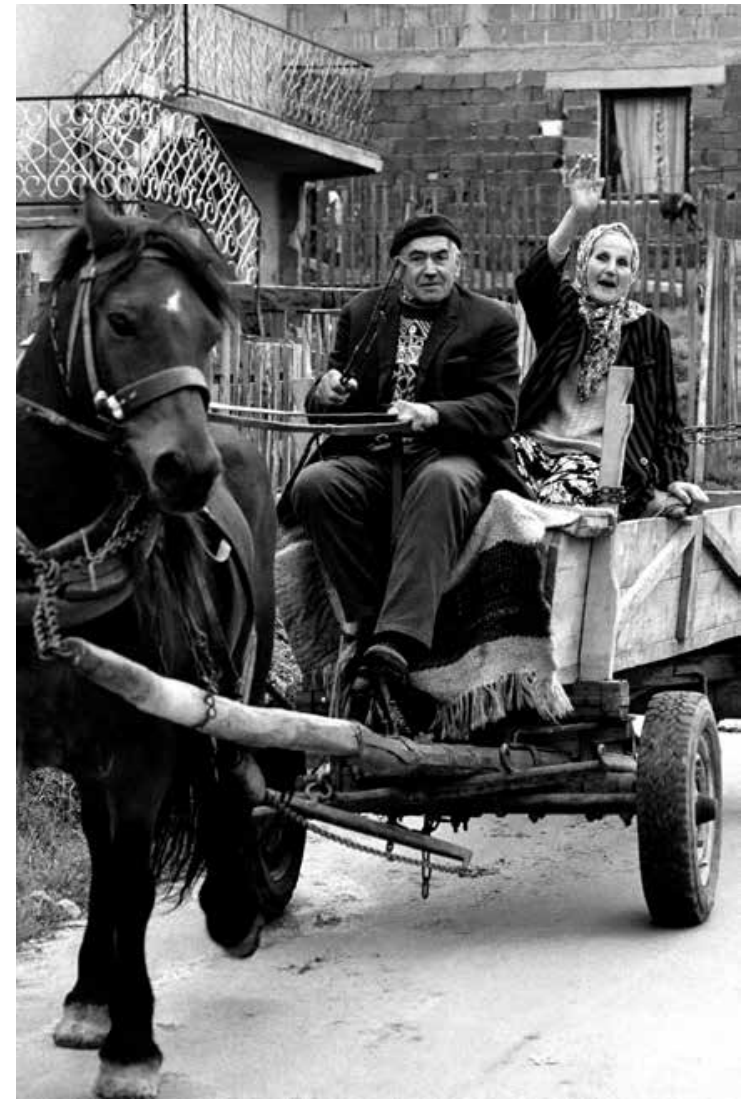

RICARDo RAMIREZ ARRIOLA $/ 360^{\circ}$ - Pareja rom, desplazados internos por la guerra. Bosnia y Herzegovina, 2000.

la Edad Moderna, con cuyo final podría ella desaparecer también” (2004: 152).

A la luz de un malestar que persiste pese a los numerosos esfuerzos de renovación historiográfica, quizá no resulte excesivo suponer que el panorama entonces aludido está en vías de materializarse, o por lo menos, de convertirse en una posibilidad concreta. ${ }^{3}$ Aunque parece prematuro, por no decir temerario, dar por saldada la modernidad, la crisis resentida apuntaría a un momento de transición susceptible de aclarar por qué el lazo entre temporalidad e historia ha comenzado a desanudarse. ${ }^{4}$ Esa progresiva no coincidencia explicaría que la disciplina sólo traduzca de manera parcial la experiencia temporal de nuestros días, al ofrecer, sin corresponderse del todo, algunas claves distintivas de este cambio de siglo. Así, por ejemplo, la dispersión del campo se encontraría en concordancia con la eclosión de temporalidades singulares, en una multiplicidad que dificulta prestar forma y sentido a la vida en común. Por otra parte, la incesante búsqueda de nuevos paradigmas que se suceden sin llegar a sedimentar podría también hallar un correlato en aquello que se ha denominado "presentismo": un tiempo "homogéneo y vacío", en el que, paradójicamente, las cosas se transforman con celeridad, pero sin alcanzar a asentarse en los estratos de la conciencia (Hartog, 2007; Benjamin, 2008).

A este mismo fenómeno se ha atribuido también el cambio en las proyecciones a futuro, un cambio perceptible al advertir que es más fácil imaginar el fin del mundo que su transformación. ${ }^{5}$ El presente se caracterizaría así por "una incapacidad constitutiva para imaginar la utopía en sí, y esto no debido a un fallo individual en la imaginación, sino como resultado de un cierre sistémico, cultural e

En ese sentido corren también las reflexiones de Hans Ulrich Gumbrecht, cuando afirma que el tiempo "parece revelar una nueva estructura y desplegarse en un ritmo diferente al tiempo 'histórico' que rigió los siglos XIx y xx. En este nuevo cronotopo [...], la agencia, la certeza y el progreso histórico de la humanidad se han disuelto en la memoria lejana. Sólo nos queda el deseo irredento, la incertidumbre y la desorientación. Al mismo tiempo un futuro que nunca elegimos nos amenaza" (2013: 38).

4

"Si la 'modernidad' ya no es una cantidad aprobable de la autointerpretación de las sociedades altamente industrializadas, entonces también la historia pierde progresivamente su significado, así parece ser, como posibilidad de estas sociedades de hacerse una imagen de sí mismas a partir de recuerdos y de diseñar su futuro de manera estimulante para la acción" (Rüsen, 2000: 429).

5 La esperanza, se pregunta a contracorriente Jocelyn Benoist, "¿no puede declinarse en tiempo presente? ¿No hay un modo de presencialidad del porvenir?" (2004: 215) [la traducción es nuestra]. 
ideológico del que todos somos de un modo u otro prisioneros" (Jameson, 2005: 345). Como reacción al impasse del tiempo venidero es posible interpretar aquellas tendencias que convierten el pasado en una moda, mediante una suerte de nostalgia que depende del mercado para actualizarse. Los mecanismos estetizantes que distinguen la ola vintage permitirían, en ese sentido, encubrir la falta de conciencia histórica, al acercar una lejanía sin producir apropiación ni reconocimiento, sino sólo una contemplación pasiva ante lo que fue y puede regresar como magia de consumo. Lejos de constituir gestos aislados, este tipo de prácticas sugiere una desestructuración del tiempo asociado con la modernidad, entendida como edad de la Historia, y con las formas de subjetividad que le son propias. ${ }^{6}$ De ahí que, al suspenderse la dialéctica entre continuidad y discontinuidad, parezca disolverse de igual modo el dinamismo histórico que le es concomitante. Así lo indican los diagnósticos contemporáneos, al referirse a un presente que no deja de sustituirse a sí mismo, sin por ello abrirse a un mañana distinto del de la repetición, el desarrollo o la radicalización de sus propias lógicas; a un futuro subsumido en una época que, con sus recursos y potencialidades técnicas, se concibe a sí misma como depurada de las expectativas soteriológicas del porvenir; y por último, a un pasado que, pese a su carácter puntual, pretende ocupar toda la extensión del tiempo (Benoist, 2004: 233).

Ante el avance de nuevas formas de experiencia temporal, el reto consistiría en servirse de la coyuntura, no sólo para registrar, sino para poner en crisis la concepción misma de tiempo histórico, esto es, para hacer una crítica del concepto en la doble acepción que se ha mencionado. Ello implicaría pensar en una historicidad que no se reduzca a admitir que hubo un antes y habrá un después. En tanto operación cognitiva y material en la cual las existencias colectivas pueden reconocerse a la vez idénticas y diferentes entre sí, la historicidad presupone una concepción del tiempo y el devenir, así como de los modos concretos de habitarlos, vivirlos y experimentarlos (Agamben, 2007). Dicho concepto supondría, por consiguiente, no sólo representar el ritmo vital en movimiento, sino reconocer la actualidad de lo pasado en lo presente. Ahora bien, en un contexto marcado por el presentismo, ¿qué actualidad puede tener lo que ha sido en el ahora? ¿Corresponde a la historia como disciplina convertirse en un factor - por oposición a sólo un efecto- de la experiencia temporal? ¿Qué papel juega la operación historiográfica en un momento de desfase entre el régimen de temporalidad y el régimen de historicidad? Éstas son algunas de las preguntas que rigen este breve ensayo. Para intentar responderlas se examinará una dimensión crucial de la experiencia y sus formas de representación como se plasman en la historia. Se trata de la violencia, caso límite que obliga a repensar cómo se inscribe la temporalidad en nuestros días, y por lo mismo, quizá permita evaluar la pertinencia y el alcance de nuevas formas narrativas.

6

Un ejemplo de este tiempo típicamente moderno aparece en la caracterización de Norbert Elias, para quien la noción designa un medio orientador desarrollado por medio de la experiencia, en un proceso de aprendizaje que se realiza con el curso de las generaciones. "La percepción de acontecimientos que se dan como una sucesión en el tiempo presupone que hay en el mundo seres vivos que, como los hombres, son capaces de recordar de una manera unívoca lo sucedido con anterioridad y de verlo con una mirada espiritual, en un cuadro único, junto con lo que pasó después y con lo que está sucediendo ahora" (Elias, 2010: 59). Si bien explica el tiempo histórico en términos de relaciones - por oposición a una visión sustantivista-, no alcanza a trascender parámetros como la causalidad y la simetría. Se emparenta así con aquellas concepciones que afirman que, para que algo concreto exista, hay causas previas inmediatas que lo hacen posible, o que piensan que el tiempo se divide entre pasado y futuro, y el presente es sólo transitorio. 


\section{La violencia como caso límite: definiciones en pugna y problemas en común}

Además de ser uno de los problemas más acuciantes de nuestro tiempo, en la violencia se reconocen con mayor nitidez las dificultades para pensar en el presente históricamente. Parte de los retos que implica su estudio derivan no sólo de que su acelerada generalización impide observar su carácter selectivo, pues no afecta a todos por igual, sino de las múltiples maneras en que se inflige, la magnitud de sus efectos, lo inconmensurable de sus prácticas y la dificultad para identificar a sus ejecutores. A ello se suma la necesidad de pensar más allá de la coyuntura y percibir su dimensión diacrónica al constituirse no como un simple acto de fuerza, sino como un complejo proceso histórico. En el marco de las reflexiones sobre la historia del tiempo presente, una de las interrogantes centrales radica, justamente, en las posibilidades concretas de trascender sus resultados inmediatos y analizar la violencia desde una perspectiva histórica.

Con el propósito de evitar las lecturas valorativas, que examinan las formas de violencia ya sea para evitarlas o para conjurarlas, pero sin avanzar en su entendimiento histórico, es necesario reconocer que no estamos ante un desajuste de la vida civilizada, una anomia social o una falla de las instituciones democráticas. Lejos de remitir a situaciones de excepción, se trata de un proceso constitutivo del presente que ha articulado las interacciones colectivas en las últimas décadas. Si bien las diferencias geográficas no son menores, su expansión resulta incuestionable en los órdenes tanto espacial como semántico. A ello responde el que un primer paso en el estudio consista, de modo imprescindible, en acotar la polisemia del término, en particular si se pretende sortear las trampas analíticas que supone. Para los fines de esta reflexión, se distingue la violencia de la ira y la agresividad, actos que manifiestan una pasión en la que se limita la autodeterminación y la reflexividad del ejecutor (Boedi, 2013).
Sin que se pretenda fijar definiciones unívocas, la claridad en el uso de los términos exige mayores precisiones. La ira expresa una actitud hostil hacia una situación en la que intervienen personas, objetos o ambos, prorrumpe en actos de fuerza desmesurada y busca desestructurar cuerpos y valores de uso. La agresividad, por otra parte, es una afección que actúa bajo la lógica del coraje para embestir la realidad con dureza. En la violencia, en cambio, se intenta imponer una situación, así como las maneras de valorarla por medio de una o más fuerzas - materiales, simbólicas, cognitivas, afectivas- En contraste con la ira, aquélla no corresponde sólo a un sentimiento ni a un acto singular; se trata, por el contrario, de una operación de cálculo en la que interviene un conjunto articulado de prácticas cuyo fin es la producción de diferencias expresadas en los cuerpos y en los objetos con los que éstos interactúan (Segato, 2010; Echeverría, 2006). Con ella, por lo tanto, no se persigue la igualdad, sino la distinción, la ruptura mediante la coacción. De ahí que no haya violencias irracionales, sobre todo si se considera que cada una posee la fuerza para producir su razón y sus procesos de entendimiento, morales o cognitivos.

Dado que sólo pueden comprenderse las formas de violencia en el marco de historicidad en que se realizan (Benjamin, 2010), la crítica histórica se presenta como una vía para pensar en el conjunto de relaciones sociales que la acompañan y la hacen posible. En el caso contemporáneo, es necesario reconocer su amplio carácter comunicativo, estructurador de sentidos y significados, en la medida en que la violencia no sólo forja signos, sino que elabora estructuras semánticas complejas. Entre sus principales rasgos, se cuenta el de poseer un doble plano de operación, al hacerse concreta sobre los cuerpos al mismo tiempo que trabaja sobre la producción de sentidos —en la triple acepción del término, es decir, como dirección, significación y sensibilidad-. De esta manera, la violencia crea presencias y determina las posibilidades de su 
representación. La marca contemporánea de estas presencias es, paradójicamente, la ausencia, propia de las violencias clandestinas y anónimas, de operaciones en las sombras de las que no quedan testigos ni experiencias (Nancy, 2006). También se plasma cuando los ejecutores siguen un lógica serial, de impronta industrial.

Una alternativa para reconstruir este fenómeno desde un punto de vista histórico aparece en las estéticas de la violencia, esto es, en las esferas sensibles y comunicativas que ésta va abriendo a su paso. ${ }^{7}$ A contracorriente de la estetización política y de la anestesia social, entendida como cierta insensibilidad o clausura colectiva ante los horizontes de sentido, historiar la violencia contemporánea a partir de su dimensión estética permite detenerse en las relaciones contenciosas y no sólo en los efectos y los afectos. La experiencia, tema caro para este tipo de estudios, emerge como un elemento central al momento de emprender el análisis. Ahora bien, mientras gran parte de los trabajos en la materia se centra en la víctima, sin atender el plano colectivo que sostiene toda vivencia, el ángulo que aquí se plantea busca examinar no sólo las significaciones, sino la materialidad que las hace posibles. La propuesta consiste, por consiguiente, en vincular las reflexiones estéticas sobre la violencia y los análisis históricos, en consonancia con el llamado que hacía Primo Levi (2003) en relación con el estudio del nacionalsocialismo. Al referirse a los límites que entrañaba la comprensión de este periodo a partir de las operaciones historiográficas tradicionales, advirtió que "es probable que se trate de una insuficiencia del texto documental; éste no tiene casi nunca el poder de restituirnos el fondo de un ser humano: a tal efecto, más idóneos que el historiador o el psicólogo son el dramaturgo o el poeta" (2003: 33). A la luz de la experiencia de nuestros días, en la cual la violencia aparece como un elemento constitutivo de la experiencia temporal y no como un fenómeno aislado o puntual, hoy tenemos que decir, sin embargo, que ambas funciones son necesarias, la del historiador y la del poeta.

Ahora bien, ¿cómo reorganizar la representación histórica cuando en el centro del debate se sitúan ausencias, de cuerpos o personas? Desde la segunda mitad del siglo Xx se ha verificado un abandono tendencial del cuerpo como referente en las representaciones de la violencia, con lo cual se inaugura una estética ajena a la dimensión corporal. Esta mudanza lleva implícito un problema: ¿cómo representar los cuerpos, resultado de violencias anónimas o clandestinas? Pese a que los restos, en caso de subsistir, sirven como indicios, se trata de fragmentos que no permiten pensar en la persona — con nombre, identidad y situación social — ni en sus relaciones colectivas. En cuanto la corporalidad se disuelve, nos encontramos ante meras proyecciones, sombras y espectros. Este tema aparece, no ya como un tropo literario, sino como un problema filosófico y social. Hablamos de fantasmas y con los fantasmas, porque están sobre nosotros a la vez que pertenecen a alguien (Derrida, 1995). Dicho diálogo produce una dislocación del tiempo histórico, en la medida en que supone existencias presentes

$7 \quad$ La dimensión estética presente al momento de construir explicaciones del tiempo social remite a la idea de la estesis como percepción y sensibilidad peculiar, asociada, a su vez, a un proceso de entendimiento en un sentido doble: producir percepción y recibir percepción, hacer algo susceptible de percibirse y disponerse a percibir. De esta forma, la estética implica la tríada sentir-percibir-conocer; se experimenta, se dispone - prepara- para percibir y se sistematiza en un tipo singular de conocimiento, todo ello conforme a un camino también doble: el de consumo y el de producción. La participación activa de los sujetos del acto estético es primordial y está determinada por un equilibrio relativo de reciprocidades, entre percibir y producir percepción. De aquí que se hable de formas estéticas de producción como una manera peculiar de establecer relaciones entre sujetos y objetos, entre sujetos y sujetos, y entre objetos y objetos como parte de una reconstrucción interpretativa del tiempo histórico. 
no contemporáneas, asincrónicas. El fantasma nos mira desde un tiempo exterior, desde la no corporalidad y desde su no persona, pero nosotros, ¿lo podemos ver? ¿Qué mecanismos hay que poner en práctica para mirar a los espectros? ¿Cómo hablar con ellos para reinstalar cualquier exceso que intente ocultar la falta? Tales son algunas preguntas fundamentales para una historia del tiempo presente, no sólo porque seguimos rodeados de espectros, sino porque no dejan de multiplicarse.

\section{Violencia, historia y representación}

En su calidad de situación a la vez normal y extraordinaria, la violencia aparece como un caso extremo entre los objetos que competen al historiador, enfrentado ex officio a meras sombras del pasado. Al no diferenciarse en términos cualitativos, sino sólo de grado, este fenómeno destaca porque atrae la atención hacia ciertos problemas inherentes a la disciplina, si bien con frecuencia soslayados debido a la naturalidad con que suele lidiarse con ellos. Centrarse en la violencia invita, por consiguiente, a hacer visible aquello que en ocasiones la costumbre y en otras las inercias colocan en el ámbito de lo invisible, empezando por el lugar que ocupa el propio historiador y el régimen temporal en que se inscribe. De ahí que la especificidad de este enfoque resida en proceder por una especie de rodeo, en el que lo ajeno desemboca en lo propio y lo familiar se redescubre en la extrañeza. Dar un paso hacia atrás - o a un costado, según preconizaba Michel de Certeau (2006) - con el fin de desnaturalizar el pasado y relativizar el presente constituye, a muy grandes rasgos, el modus operandi de esta apuesta interpretativa.

Si bien avanzar de lo desconocido a lo conocido supone invertir, al menos en apariencia, la ruta más común en la construcción del saber, recorrer el camino a contraflujo de las prácticas corrientes

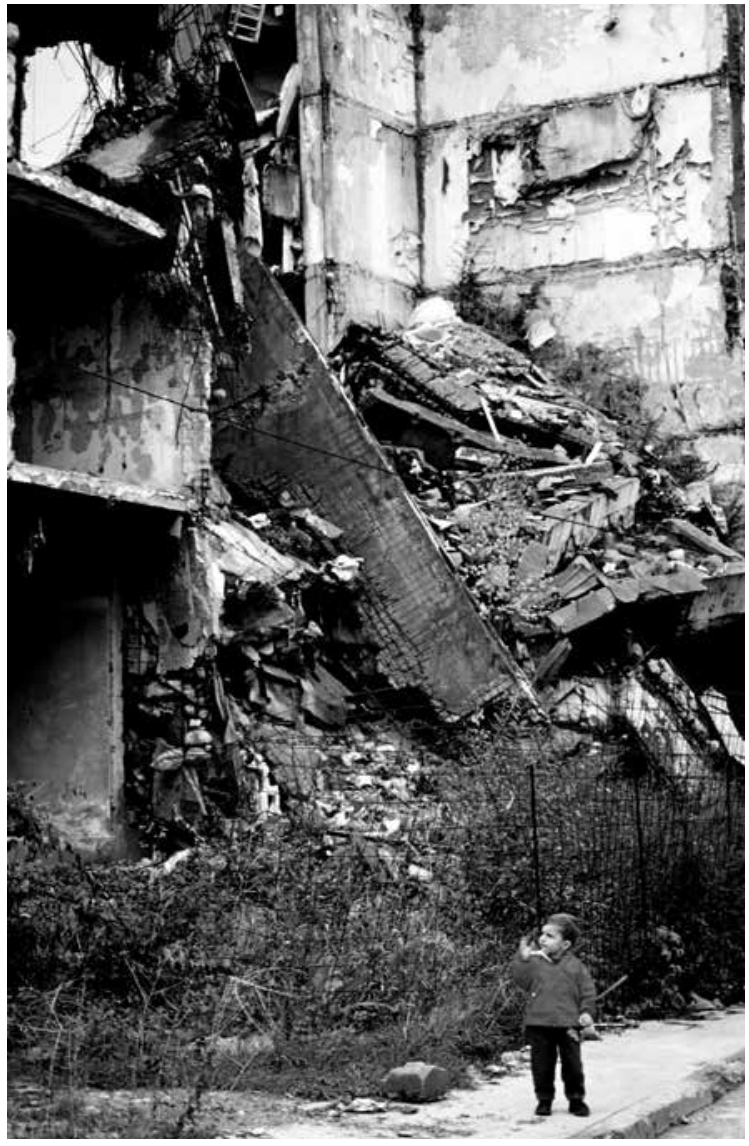

RicARdo RAmírez ARRIOLA/360 • Los impactos de la guerra en Sarajevo, Bosnia y Herzegovina, 2000.

obedece a la necesidad de disipar una ilusión que pretende convertir la cercanía en una garantía de comprensión. Por lo demás, no hay nada más opuesto a la experiencia ordinaria. Aunque la lección suele pasar inadvertida, aquella nos enseña que, a mayor proximidad, lo visible tiende a tornarse invisible. Por obra del contacto constante, las imágenes de nuestro pasado y nuestro presente se transforman, de acuerdo con una metáfora de François Hartog, en "retratos de familia tan familiares que ya no los vemos" (2011: 87). De ahí que el problema no consista sólo en la dificultad de restituir una ausencia, sino también en la exigencia de devolver la 
visibilidad a una presencia. Colocar el entorno bajo una luz inusual, de modo que se imponga de nuevo a la conciencia, es una propiedad de la violencia en tanto campo de experimentación susceptible de poner a prueba tanto las herramientas historiográficas comunes, como los alcances del conocimiento histórico. Este hecho se confirma al advertir que tomarla por objeto nos obliga a repensar el tiempo histórico, entendido como el punto en que confluyen las distintas temporalidades colectivas. Puede de este modo llegar a esclarecer la experiencia temporal contemporánea, ubicada, según Hans Ulrich Gumbrecht, bajo el signo de la latencia:

En una situación de latencia, cuando lo encubierto (stowaway) está presente, sentimos que algo (o alguien) está ahí sin que lo podamos asir o tocar - y que este "algo" (o alguien) se articula materialmente, por lo que ocupa espacio-. Somos incapaces de decir de dónde proviene, exactamente, nuestra certeza de la presencia, ni sabemos con precisión dónde se localiza ahora lo latente. Y dado que no sabemos la identidad del objeto o persona latentes, nada nos garantiza que reconozcamos ese ser si alguna vez aparece. Más aún, lo latente puede experimentar cambios mientras permanece oculto. Lo encubierto (stowaway) puede envejecer, por decir un ejemplo. Sobre todo, no hay razón para creer —o al menos no una razón sistemática- que lo que ha ingresado en un estado de latencia aparecerá o, a la inversa, que no será olvidado algún día (2013: 23).

Pese a que, según Gumbrecht, "no hay 'métodos' o procedimientos estándar —y desde luego ninguna interpretación - que nos permita recuperar lo que ha pasado a la latencia" (2013: 23), una alternativa para reformular el problema y tratar de idear respuestas consiste en atender las lecciones de la antropología de la imagen (Belting, 2012). Ésta nos enseña que las imágenes funcionan como un medio para reconocer lo idéntico a partir de la diferencia, es decir, para reconocer nuestro propio cuerpo por medio de otro. La imagen del cuerpo como problema para la historia de la violencia es central para replantear las posibilidades de la representación. Una manera de acercarse a ella desde una perspectiva antropológica y atisbar las dificultades que conlleva aparece en la metáfora del espejo: el espejo permite ver cuerpos donde no los hay, dado que sólo captura imágenes y miradas sobre éstas (Silverman, 2009). Por obra de la refracción, proyectamos sobre nuestros cuerpos lo que pertenece a otros, en este caso, aquellos cuerpos ausentes a causa de la violencia. Por consiguiente, una historia del tiempo presente debe aprender a trabajar con sombras que manifiestan la presencia de un cuerpo, en su doble calidad de formador y receptor de opacidades. La pregunta de partida, sin embargo, sigue sin encontrar respuesta, dado que, en efecto, ¿cómo representar sombras? Una posible salida estribaría en poner el propio cuerpo, si bien ésta no carece de ambigüedad en la medida en que de este modo se señala y al mismo tiempo se multiplica una ausencia. Pese a ello, sólo así el espectro abandona su condición perturbadora, al convertirse en una imagen que nos identifica.

Las sombras pueden interpretarse como la manifestación de una presencia no contemporánea, como el gesto de traer al ahora un tiempo exterior. Representarlas funciona como un medio para construir un puente entre el no ser y el ser, entre los que no están — negados doblemente, en su condición de personas y por no haber restos de ellos- y quienes están reconociendo esa falta. Es posible disolver así el equívoco que consiste en dejarse fascinar o repeler ante la imagen de un cuerpo desmembrado, sin advertir que ésta no constituye una ruptura, sino una extensión de la violencia. Ello responde a que este tipo de imágenes se presta como un canal para prologar tanto la violencia como las relaciones colectivas que los cuerpos mutilados o 
aniquilados representan (Sontag, 2004). En cambio, trabajar con sombras obliga a transgredir el orden que normaba lo visto y lo no visto, lo susceptible de presentarse y de socializarse. Ellas capturan imágenes y organizan miradas sobre la violencia. La sombra que se abre hacia una lectura del tiempo social es una sustitución que restituye la realidad histórica, un singular universal de las formas de violencia (Grüner, 2008). De este modo, nos permite acercarnos mediante la identificación y la empatía a la experiencia histórica de miles de personas, al remitir a un fenómeno en común, a saber, la violencia como mecanismo de articulación social. Representar sus efectos sobre los cuerpos puede contribuir a crear una dimensión social y conciencia histórica donde antes no había sino puro presente.

\section{A modo de cierre: presente e historia}

Roger Chartier escribió: "la especificidad de la historia, dentro de las ciencias humanas y sociales, es su capacidad de distinguir y articular los diferentes tiempos que se hallan superpuestos en cada momento histórico" (2007: 88). De ahí que "la lectura de las diferentes temporalidades que hacen que el presente [sea] lo que es, herencia y ruptura, invención e inercia a la vez, [siga] siendo la tarea singular de los historiadores y su responsabilidad principal para con sus contemporáneos" (2007: 93). La pregunta por la historicidad de la violencia constituye una manera de asumir dicho deber, en la medida en que presupone una reflexión sobre el propio tiempo de la historia. Explorar las posibles respuestas nos obliga a admitir, en un primer término, que aquella que se ocupa del presente no se reduce al estudio de una época en particular - en el caso más conservador, la época contemporánea-. Lejos de reducirse a un factor cronológico, la historia del tiempo presente funciona como un mecanismo de distanciamiento y como una forma de reconocimiento analítico capaz de replantear el significado de los tiempos históricos.

En lugar de un presente meramente efímero, punto transitorio que separa el pasado y el futuro, se requiere una idea del tiempo histórico como contingencia. Reconocer que éste no se manifiesta como un proceso necesario, sino como la resolución imprevisible de potencias en disputa, significa que la historia es la expresión de lo que fue y de lo que pudo ser, de la potencia y la impotencia de las interacciones entre formas de vida colectivas. Desde luego, no se trata de invitar a ingresar en el reino del posibilismo ni a centrarse en las condiciones azarosas que subyacen en el acontecer. Concebir la historia desde las potencias equivale a admitir, simplemente, que ésta no se agota en los actos. En palabras de Giorgio Agamben:

La interpretación que proponemos nos obliga a pensar de un modo nuevo y no trivial la relación entre potencia y acto. El pasaje al acto no anula ni agota la potencia, sino que ella se conserva en el acto como tal y, marcadamente, en su forma eminente de potencia de no (ser o hacer) (2008: 299).

Por lo tanto, la condición de toda historia es la ambigüedad, aquello que determina que algo pueda o no ser, y cuya realización es evanescente, mas no arbitraria ni azarosa. Sólo en el presente se resuelven las ambigüedades, con lo cual surge como una evidencia que éste constituye el tiempo histórico por excelencia y no el pasado, como suele afirmarse.

El presente es aquello que Walter Benjamin caracteriza como una dialéctica en suspenso, el momento preciso en que las potencias del tiempo histórico se encuentran:

Todo presente está determinado por aquellas imágenes que le son sincrónicas: todo ahora es el ahora de una determinada cognosibilidad. En él, la verdad está cargada de tiempo hasta estallar. No 


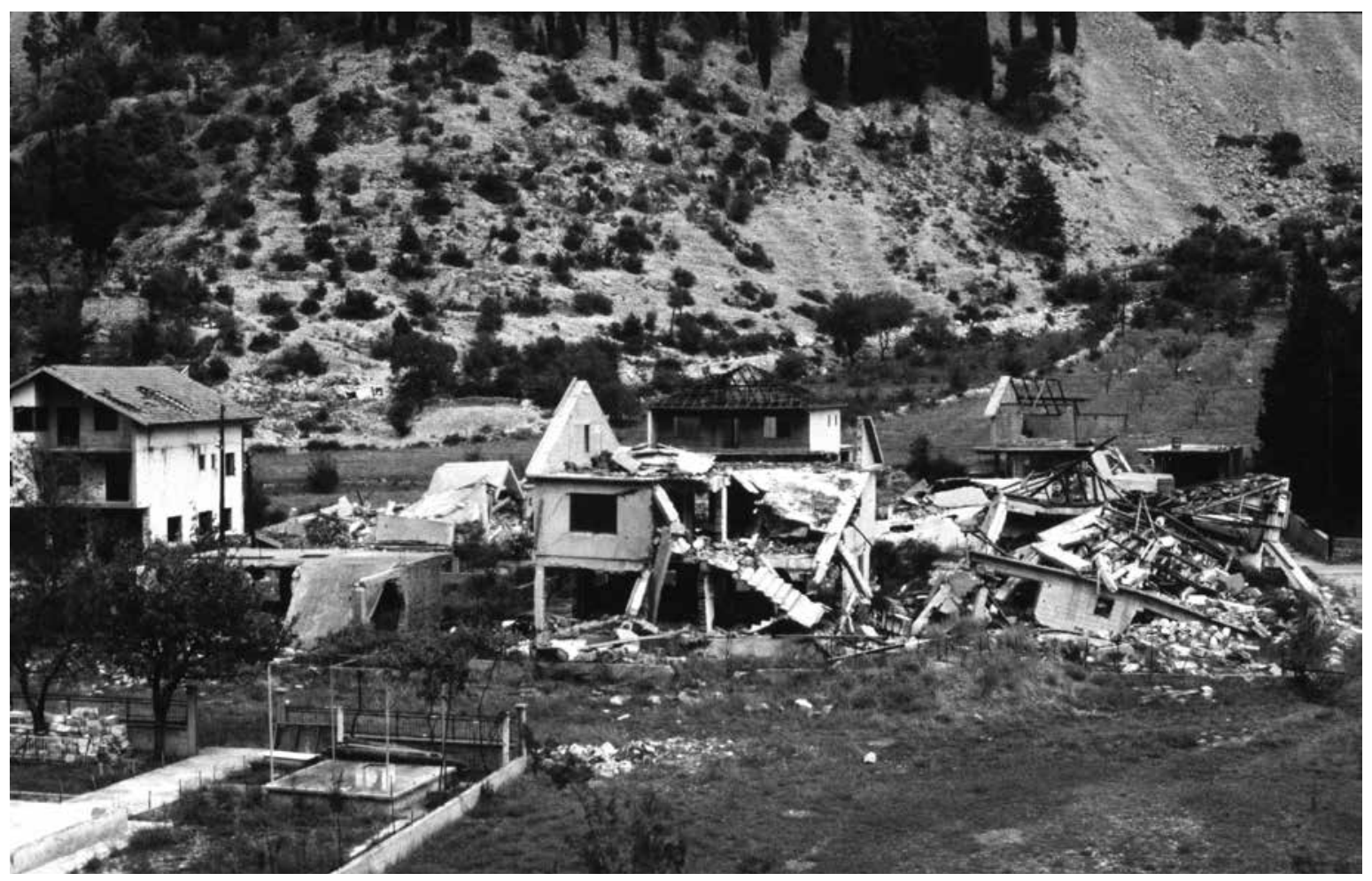

RicARdo Ramírez ArRIOLA/360 Camino a la República Srpska, una de las dos entidades de Bosnia y Herzegovina, 2000.

es que lo pasado arroje luz sobre lo presente, o lo presente sobre lo pasado, sino que la imagen es aquello en donde lo que ha sido se une como un relámpago al ahora en una constelación. En otras palabras: imagen es la dialéctica en reposo. Pues mientras que la relación del presente con el pasado es puramente temporal, la de lo que ha sido con el ahora es dialéctica: de naturaleza figurativa, no temporal. Sólo las imágenes dialécticas son imágenes auténticamente históricas, esto es, no arcaicas. La imagen leída, o sea, en el ahora de su cognosibilidad, lleva en el más alto grado la marca del momento crítico y peligroso que subyace en toda lectura (2005: 465).

Esta tensión aparece ilustrada en la idea de una constelación: aquella suma de estrellas en el firmamento cuya luz es de distinta naturaleza. Pese a que algunas de ellas son jóvenes y otras se han extinguido, a partir de su destello conjunto podemos construir una imagen en el presente. ¿Quién construye esa imagen sino el historiador, quien al reconocer los tiempos asincrónicos les infunde sincronía? Así también, toda imagen posee un índice de historicidad que revela tanto su tiempo de procedencia como el tiempo de su legibilidad, esto es, el momento en el que las potencias entran en juego. Para alcanzar uno y otro se requiere una dialéctica que ponga en operación un acercamiento histórico y político. En ese sentido, Benjamin advirtió:

La penetración dialéctica en contextos pasados y la capacidad dialéctica para hacerlos presentes es la prueba de la verdad de toda acción contemporánea. 
Lo cual significa: ella detona el material explosivo que yace en lo que ha sido. Acercarse así a lo que ha sido no significa, como hasta ahora, tratarlo de modo histórico, sino de modo político, con categorías políticas (2005: 397).

A ello es dado añadir que el vínculo político entre la historia y el presente no remite a una acepción reduccionista de la política, entendida como una operación de especialistas, la clase política, que dirige los rumbos de la vida social. Lo político, en este caso, remite a una dimensión más simple y extensa: la capacidad colectiva de dar forma y sentido a la vida en común. Se trataría de una acción paradójica, en la que el índice del tiempo histórico se hace actual, en la que lo que ha sido sirve para configurar el ahora, para producir materialidades y semánticas de la vida en común.

Ahora bien, si el tiempo histórico por excelencia es el presente, también es susceptible de entenderse mediante las operaciones que se instrumentan para acercarnos al pasado. Ambas dimensiones temporales comparten lo inacabado: si, por una parte, el pasado no deja de ser actual, por la otra, el presente, además de evanescente, es siempre una apertura a lo potencial. Desde esta perspectiva, el historiador del tiempo presente no estaría obligado a buscar los orígenes ni las causas de las presencias contemporáneas, como tampoco lo está en relación con el pasado. La diferencia cualitativa reside en que la sincronía de las potencias asincrónicas es más problemática en el presente, porque su destello es más difícil de reconocer y de entender. Dicha diferencia no es menor, pero no presupone una imposibilidad para concebirlo como tiempo histórico. El desafío sería, por lo tanto, de naturaleza política y epistémica: política, porque obliga a pensar la función social del historiador y la operación historiográfica como parte de la configuración de la vida colectiva; epistémica, debido a que demanda no sólo herramientas renovadas y múltiples, sino, sobre todo, una capacidad de lectura de los índices de historicidad en el presente.

Ante estas perspectivas y reconceptualizaciones, ¿cómo hacer una historia del tiempo presente? ¿Qué operaciones historiográficas podrían ponerse en práctica y cuáles son sus posibilidades de éxito? Una alternativa para afrontar el reto consiste en reconocer los índices de historicidad que se hacen actuales a la manera de una cita, es decir, en incorporar su presencia en la imagen del tiempo presente. Para entender este proceso, recordemos su definición y doble modo de funcionamiento. Por un lado, la cita, en su sentido cronológico, se entiende como una intención y un compromiso por encontrarse en un tiempo determinado; por el otro, también puede comprenderse como la reproducción de un fragmento enunciativo y expresivo en un contexto distinto a aquel en el cual se produjo. En el primer caso, la cita no es una relación contractual, establecida de antemano entre las partes, sino un encuentro afortunado o desafortunado que era esperado, mas no programado. Es una especie de "secreto compromiso de encuentro" que "está entonces vigente entre las generaciones del pasado y la nuestra” (Benjamin, 2008: 37). En ese marco de interpretación, la cita adquiere la forma de un llamado — vocación - entre tiempos históricos en apariencia inconexos. Se trata de un llamado plural que convoca y encierra las potencias e impotencias de las vidas pretéritas, para anunciar así la posibilidad de una transformación - revocación-. Tal es la dimensión política contenida en el acto de citar el pasado en el presente. De este modo, coincidimos con Hans Blumenberg, al afirmar que "la exigencia a la historia del otro es como la autoconservación sobre la base de la reciprocidad" (2007: 263).

En cuanto a la cita como reproducción, constituiría el momento epistémico que hace posible leer en el ahora lo que ha sido en el ayer. En este segundo caso, no opera bajo el principio de la identidad, sino en el de la negatividad, el de la diferencia radical con 
aquello a lo que se hace presente. Por ello, toda cita tiene algo tanto de destrucción como de creación, en la medida en que no conserva el original al cual hace referencia, sino que detona significaciones inéditas en el presente. Se trata, por lo mismo, de una apropiación, sin que ello la convierta en un gesto arbitrario. Su principal característica reside, más bien, en la capacidad de confrontar épocas distantes, dado que extrae lo citado de su contexto para volver a dotarlo de actualidad. De ahí que le confiera nueva vida al hacerlo sobrevivir. Todo ello, desde luego, a condición de descubrir "en la cita una fuerza no de conservar, sino más bien de purificar, y de destruir y sacar de contexto; la única que infunde todavía la esperanza de que algunas cosas sobrevivan a este escaso espacio temporal, precisamente porque las han sacado de él" (Benjamin, 2007b: 374).

La cita, en su doble dimensión, alberga un nudo problemático en el que se sincronizan el pasado y el presente, un nudo que podría equipararse a la tensión intrínseca entre el tiempo de la vida y el tiempo del mundo. Según Hans Blumenberg (2007), sería posible plantear que una y otro poseen una cronometría irreconciliable, dado que el tiempo vital nunca alcanza el paso marcado por el tiempo mundano. Pese a que sus finitudes son cualitativa y cuantitativamente diferentes —el tiempo del mundo es inconmensurable para el tiempo de la vida y ésta siempre llega tarde al mundo-, ambos registros temporales comparten una condición en común: su historicidad. En los dos casos, su condición histórica se materializa en un tiempo entrecruzado y limitado. De hecho, si algo tienen de eterno es su carácter incompleto: uno y otro están continuamente llamados a completarse. Tanto en el mundo como en la vida, los esfuerzos por alcanzar la completitud construyen un presente, un estado de detenimiento. De este modo, los entrecruzamientos del tiempo en el presente producen semejanzas y correspondencias entre aquellas potencias que encarnan el devenir (Benjamin, 2007a).

La historicidad, como tiempo presente, es un acto de espera, de por venir, en el que se configura el camino de lo posible. En ella, el acontecer no sigue un curso homogéneo y vacío, sino que se produce una ruptura radical:

Uno no debe dejar pasar el tiempo, sino que debe cargar tiempo, invitarlo a que venga a uno mismo. Dejar pasar tiempo (expulsarlo, rechazarlo): el jugador. El tiempo le sale por todos los poros. Cargar tiempo como una batería carga electricidad: el $f$ la neur. Finalmente el tercero: cargar el tiempo y lo vuelve a dar en otra forma - en la de la expectativa—: el que aguarda (Benjamin, 2005: 133).

Asumir la radicalidad del presente como tiempo histórico constituye una condición para restituir la esperanza de un tiempo futuro que sea distinto al que ahora vivimos. De no aceptarse su historicidad, y por lo tanto, su necesario acercamiento crítico, difícilmente habrá expectativas del porvenir o experiencias del pasado. Lo único que nos quedaría, entonces, es el presentismo, un tiempo homogéneo y vacío en el que las existencias no logran vincular el tiempo vital con el tiempo de la historia. D

\section{Bibliografía}

Agamben, Giorgio, 2007, Infancia e historia. Destrucción de la experiencia y origen de la historia, Adriana Hidalgo, Buenos Aires.

__, 2008, "La potencia del pensamiento", en La potencia del pensamiento. Ensayos y conferencias, Anagrama, Barcelona, pp. $285-299$.

Belting, Hans, 2012, Antropología de la imagen, Katz, Buenos Aires.

Benjamin, Walter, 2005, El libro de los pasajes, Akal, Madrid. 
2007a, "Hacia la imagen de Proust”, en Obras, libro II, vol. 1, Abada, Madrid, pp. 317-331.

2007b, "Karl Kraus", en Obras, libro II, vol. 1, Abada, Madrid, pp. 341-376.

2008, Tesis sobre la historia y otros fragmentos, Itaca/Universidad Autónoma de la Ciudad de México, México.

2010 [1921], Crítica de la violencia, Biblioteca Nueva, Madrid.

Benoist, Jocelyn, 2004, "Créer l'avenir, ou la révolution sans utopie”, en Jocelyn Benoist y Fabio Merlini (eds.), Une historie de l'avenir. Messianité et Révolution, Vrin, París, pp. 211-228.

Blumenberg, Hans, 2007, Tiempo de la vida y tiempo del mundo, Pre-Textos, Valencia.

Boedi, Remo, 2013, La ira: pasión por la furia, Antonio Machado, Madrid.

Borges, Jorge Luis, 1993, Ficciones. El Aleph. El informe de Brodie, Biblioteca Ayacucho, Caracas.

Certeau, Michel de, 2006, La debilidad de creer, Katz, Buenos Aires.

Chartier, Roger, 2007, La historia o la lectura del tiempo, Gedisa, Madrid.

Derrida, Jaques, 1995, Espectros de Marx. El Estado de la deuda, el trabajo del duelo y la nueva Internacional, Trotta, Madrid.

Echeverría, Bolívar, 2006, "De violencia a violencia”, en Bolívar Echeverría, Vuelta de sig/o, Era, México, pp. 59-80.

Elias, Norbert, 2010, Sobre el tiempo, Fondo de Cultura Económica, México.

Grüner, Eduardo, 2008, “La invisibilidad estratégica o la redención política de los vivos”, en Ana Longoni y Gustavo Bruzzone (comps.), El siluetazo, Adriana Hidalgo, Buenos Aires, pp. 285-308.

Gumbrecht, Hans Ulrich, 2013, After 1945. Latency as Origin of the Present, Stanford University Press, Stanford.

Hartog, François, 2007, Regímenes de historicidad. Presentismo y experiencias del tiempo, Universidad Iberoamericana, México.

__ 2011, Evidencia de la historia. Lo que ven los historiadores, Universidad Iberoamericana, México.

Jameson, Fredric, 2005, Arqueologías del futuro. El deseo llamado utopía y otras aproximaciones de ciencia ficción, Akal, Madrid.

Koselleck, Reinhart, 2004, historia/Historia, Trotta, Madrid.

2007, Crítica y crisis. Un estudio sobre la patogénesis del mundo burgués, Trotta, Madrid.

Leonhard, Jörn, 2013, “Lenguaje, experiencia y traducción: hacia una dimensión comparativa”, en Javier Fernández Sebastián y Gonzalo Capellán de Miguel (eds.), Conceptos políticos, tiempo e historia. Nuevos enfoques en historia conceptual, Ediciones de la Universidad de Cantabria/McGraw-Hill, Santander y Madrid, pp. 377-404.

Levi, Primo, 2003, "Auschwitz, ciudad tranquila", en Última navidad de guerra, Aleph, Barcelona, pp. 33-38.

Nancy, Jean-Luc, 2006, La representación prohibida, Amorrortu, Buenos Aires, pp. 15-72.

Rüsen, Jörn, 2000, “Ilustración histórica de cara a la posmodernidad: la historia en la era de la 'Nueva dispersión'”, en Silvia Pappe (coord.), Debates recientes en la teoría de la historiografía alemana, Universidad Autónoma Metropolitana-Azcapotzalco, México, pp. 427-456.

Segato, Rita, 2010, “La estructura de género y el mandato de violación”, en Rita Segato, Estructuras elementales de la violencia: ensayos sobre género entre la antropología, el psicoanálisis y los derechos humanos, Prometeo, Buenos Aires, pp. 21-52.

Silverman, Kaja, 2009, El umbral del mundo visible, Akal, Madrid.

Sontag, Susan, 2004, "Regarding the Torture of Others", en The New York Times Magazine, 23 de mayo. Disponible en línea: <http://www. nytimes.com/2004/05/23/magazine/regarding-the-torture-of-others.html?_r=0>. 